\title{
SUJETOS SOCIALES, ESCUELAS Y COMUNIDADES RURALES. DISPUTAS DE PODER EN EL ESCENARIO DE LA CAMPAÑA BONAERENSE $(1810-1875)^{\&}$
}

\author{
Social Subjets, Schools and Rural Communities. Disputes of Power \\ in the Scenario of the Buenos Aires Campaign (1810-1875)
}

\section{Lucía Lionetti*}

Fecha de recepción: 07/04/2017 • Fecha de aceptación: 27/09/2017

Resumen. ¿Qué tipo de escuelas existieron en una sociedad de frontera signada por la ruralidad, la inestabilidad política y un fluido contacto inter e intra étnico? ¿Con qué propósitos fue pensada esa escolarización y que lugar ocupó en la conformación del orden político? ¿Qué tipo de relaciones se entretejieron entre las autoridades civiles, religiosas, los vecinos y preceptores? Estos interrogantes son los disparadores a partir de los cuales se analiza la presencia de las escuelas elementales en la campaña bonaerense (provincia de Buenos Aires) en el siglo XIX. Bajo la iniciativa de extender la marca civilizadora de la alfabetización, sobre un mundo percibido como bárbaro y salvaje que habría promovido la «ruralización de la política», se proyectó esa voluntad alfabetizadora. Los conflictos, dificultades, tipos de prácticas educativas y el perfil de los preceptores serán explorados a partir de una valiosa bibliografía en diálogo con los repositorios documentales consultados - archivos locales, prensa y documentos oficiales-. Esa escolarización rural —antes de que se conformara en la provincia el sistema de educación común, gratuito y obligatorio en 1875-

\footnotetext{
\& Este trabajo forma parte de la línea de trabajo «Escuelas, niñez y género en la campaña bonaerense, siglos XVIII al XIX», que integra el Programa: Actores, Ideas y Proyectos Políticos de la Argentina Contemporánea, radicado en el Instituto de Estudios Histórico Sociales (IEHS), financiado por la Secretaría de Ciencia, Arte y tecnología (SECAT) de la UNCPBA, y en el Instituto de Investigación de Geografía, Historia y Ciencias Sociales (IGEHCS)/CONICET-UNCPBA.

" Departamento de Historia. Facultad de Ciencias Humanas. Universidad Nacional del Centro (UNCPBA). Pinto 399, Tandil (CP: 7000), Provincia de Buenos Aires, Argentina. Correo electrónico: lionettilucia@gmail.com; lionetti@fch.unicen.edu.ar
}

Cómo citar este artículo: Lionetti, Dominga Lucía. «Sujetos sociales, escuelas y comunidades rurales. Disputas de poder en el escenario de la campaña bonaerense (1810-1875)». Historia y Memoria de la Educación 7 (2018): 47-80. 
puso en evidencia las tensiones pero también los acuerdos entre esa sociedad y sus "costumbres en común» y un orden político estatal que buscó consolidarse en la provincia.

Palabras clave: Campaña bonaerense; Comunidades rurales; Escuelas; Acuerdos; Conflictos.

Abstract. What kind of schools existed in a rural world marked as an uncivilised society with political instability and fluid inter and intra-ethnic contact? For what purposes was this schooling planned and what role did it play in shaping the political order? What relationships were interwoven between civil authorities, religions, inhabitants and preceptors? These questions are the starting point for an examination of the presence of elementary schools in Buenos Aires (Buenos Aires province) and of the initiative taken to extend the civilizing process of literacy; in a country seen as underdeveloped, this represented a sponsorship of "rural politics». Conflicts, difficulties, types of educational practices and the profile of preceptors will all be explored from a select bibliography in conjunction with the consulted document repositories - local files, press and official documents. This rural schooling, before the establishment of the common free education system in 1875, revealed tensions but also agreements between society, its "common customs» and the political power which sought to become consolidated in the province.

Keywords: Buenos Aires Campaign; Rural communities; Schools; Agreements; Conflicts.

\section{INTRODUCCIÓN}

El presente trabajo analiza la radicación de escuelas en un espacio social y tiempo concreto: la campaña bonaerense entre los años 1810 a 1875. Un recorte temporal que implica reconocer las continuidades respecto a lo que fuera el Estado Colonial y el proceso de conformación de la nueva legitimidad republicana, tras el resquebrajamiento del antiguo orden y que, en materia de instrucción pública, culminó en la provincia de Buenos Aires con la sanción de la Ley de Educación Común y Obligatoria de 1875. Esta ley fue un antecedente —más allá de que garantizaba la enseñanza de la religión católica en las escuelas- de la Ley 1420 promulgada por el gobierno nacional para la Capital Federal y los llamados Territorios Nacionales ${ }^{1}$ en 1884 , mediante la cual se garantizó

\footnotetext{
${ }^{1}$ El Territorio nacional fue un tipo de entidad política centralizada subnacional, que existió en la Argentina entre 1862 y 1985. La mayor parte de esas tierras se encontraban en poder de diversas
} 
en la Argentina la educación pública, gratuita, gradual, obligatoria y laica destinada a extender la alfabetización a todos los niños y niñas de la república.

Estas leyes contaron con antecedentes poco estudiados tales como, las iniciativas que propiciaron las autoridades y los vecinos antes de que se configuraran el Estado provincial y el nacional. En esa tarea, de crear y sostener escuelas, quedaron involucradas las autoridades civiles de turno, vecinos, curas párrocos, preceptores y, claro está, quienes fueron los destinatarios de la preocupación alfabetizadora: los niños y niñas de ese escenario social.

Como se puede registrar, la labor fue compleja frente a la falta de fondos públicos, la escasa formación de los preceptores y situaciones conflictivas, tensiones y desacuerdos que reiteradamente se producían entre los sujetos sociales involucrados. Esto implica reconocer que, la configuración del modelo de educación pública estatal — tanto en la provincia de Buenos Aires como en la nación- contó con antecedentes que no deben ser considerados solo desde una perspectiva lineal, dando cuenta de la especificidad del contexto que se estudia. Para avanzar en ese sentido, en un primer apartado, se presenta a grandes rasgos las características sociales, económicas y políticas de la campaña bonaerense. En una segunda parte, se recuperan las primeras iniciativas en favor de la radicación de escuelas elementales por parte de las autoridades civiles. Iniciativas - muchas veces acompañadas por las propias comunidades- que mostraron sus límites ante la propia debilidad política y las mediaciones que le impuso aquella realidad social. Finalmente, en un tercer apartado, se analiza el nuevo escenario de conflictos que se generaron a partir del evidente avance que promovieron las autoridades provinciales en materia de instrucción pública. Una aproximación que, permite reflexionar, a partir de la presencia de esas escuelas —y en el marco de aquel paisaje

culturas indígenas y eran, a su vez, disputadas entre Argentina y los otros países limítrofes. Los territorios nacionales constituyeron un modo de organización territorial diferente del que establecía la Constitución sobre la base de provincias, que eran autónomas y autogobernadas. Los territorios nacionales, por el contrario, eran dependientes del Poder Ejecutivo Nacional. Su población carecía de derechos políticos. Se constituyeron diez territorios nacionales, en total sumaban una superficie mayor que el que abarcaban las provincias. En la región pampeana y la Patagonia se crearon Tierra del Fuego, Santa Cruz, Chubut, Río Negro, Neuquén y La Pampa. En la región noreste del país, se crearon los territorios nacionales de Misiones, Formosa y Chaco. En la región noroeste se creó el territorio nacional de Los Andes. 
social con sus comunidades fuertes y un lábil orden político- sobre ese complejo proceso de conformación de la estatalidad moderna.

Las dificultades que se plantearon para realizar este trabajo fueron de tipo heurística-metodológicas. La escasez de fuentes oficiales que permitan recuperar las políticas educativas, la dispersión, diversidad y vacíos en el registro documental, sumado al mal estado de los reservorios documentales, son los obstáculos a superar. Sin embargo, a pesar de esos oscuros, hay indicios que permiten mostrar de qué modo, en una cartografía social eminentemente rural, hubo interés por promover la alfabetización y el acceso a una cultura letrada, condición estimada necesaria para extender los beneficios de la civilización y para promover el pasaje de la condición de súbditos de la corona a la de ciudadano de la República.

\section{LA DINÁMICA SOCIAL Y EL ORDEN POLÍTICO DE LA CAMPAÑA BONAERENSE}

¿A qué nos referimos específicamente al hablar de la campaña bonaerense? Se trata de un territorio ${ }^{2}$ que tuvo como punto de referencia el puerto y la ciudad de Buenos Aires - capital del virreinato desde 1776que comenzó un proceso que se extendería a lo largo de todo el siglo XIX marcado por el desarrollo económico y la diversificación social. A comienzos del siglo las guerras de independencia provocaron el dislocamiento del eje económico que unía el centro minero de la Villa de Potosí - actualmente territorio de Bolivia- con el puerto de Buenos Aires. ${ }^{3} \mathrm{La}$ disgregación del circuito económico, por el cual la metrópoli extraía a través del comercio y de la renta impositiva la plata potosina, provocó cambios sustanciales en la región circundante al puerto de Buenos Aires. Tras algunos años de incertidumbre, la creciente demanda de productos

\footnotetext{
${ }^{2}$ Cuando nos referimos al término territorio seguimos la definición dada por Barriera: «Un territorio es ante todo el resultado y el estado de una relación histórica de carácter político entre una sociedad, el terreno que organiza y las instituciones con las cuales se ordena esta relación. El conjunto de instrumentos jurídicos, técnicos y simbólicos que intervienen en dicha relación, las vivencias que generan y las representaciones de esas vivencias pueden denominarse la experiencia de la territorialidad», en Darío Barriera «Tras las huellas de un territorio» en De la Conquista a la Crisis de 1820. Tomo 2. Director del Tomo Raúl Fradkin. Colección Historia de la Provincia de Buenos Aires. Director: Juan Manuel Palacio. (Buenos Aires: Editorial Universitaria EDHASA, 2012), 53.

${ }^{3}$ Tulio Halperín Donghi [1972], Revolución y Guerra. Formación de una elite en la Argentina criolla (Buenos Aires: Siglo XXI, 2005).
} 
pecuarios por parte de mercados europeos hizo posible que las remesas de plata fueran reemplazadas por cueros y derivados del ganado - tasajo, sebo, crines-. La cercanía a la ciudad de Buenos Aires implicó la posibilidad de producir bienes como cereales u hortalizas para el abasto del mercado. El segundo grupo de poblados tuvo una producción mixta. Se encontraban establecimientos dedicados a la agricultura, pero ya aparece con mayor presencia el ganado. Éste sería aún más abundante hacia el tercer cinturón productivo.

Si bien no se cuenta con información precisa sobre la evolución demográfica de este espacio social, para 1815 se contabilizó la presencia de unas 43.000 personas. A partir de la década del veinte, la población de la campaña superaba a la de la ciudad de Buenos Aires que le dio origen, alcanzando unas 57.000 personas y aglutinando aproximadamente al 7,8\% del total de la población del territorio argentino. El Primer Censo Nacional de la Población en Argentina realizado en 1869 reveló que, más de 330.000 personas habitaban la campaña., duplicando a la de la ciudad de Buenos Aires. Según determina en su trabajo Gladys Massé, los valores más altos de las tasas medias anuales de crecimiento tuvieron lugar en la etapa independiente, específicamente en la década de 18601869. Superada las primeras décadas del siglo XIX, donde se observa una disminución en el ritmo de crecimiento de la población producto de las guerras de independencia y los enfrentamientos internos, se puede reconocer que, el dinamismo demográfico fue producto del paulatino establecimiento de la población en una superficie territorial en continua expansión. La evolución de la población acompañó el avance de la frontera y el incremento extensivo del uso del espacio por la incorporación de tierras a la producción agropecuaria.

Los componentes del crecimiento demográfico, natalidad, mortalidad y migraciones determinan que, durante el siglo XVIII, ese incremento se debió al fuerte predominio de la inmigración —interna y externa- más que al crecimiento vegetativo. En las primeras décadas del siglo XIX, ambos componentes vegetativo y migratorio tuvieron una contribución similar. Por último, durante el período que se inició a partir de 1840, la aceleración del crecimiento demográfico se debió a las tasas de migra- 
ción neta que superaron ampliamente el aporte del crecimiento natural de la campaña. ${ }^{4}$

Si bien no se dispone de series de nacimiento y defunciones para la totalidad de la provincia de Buenos Aires, se puede confirmar que los valores alcanzados desde mediados del siglo XIX corresponden a un régimen demográfico pretransicional caracterizado por altos niveles de natalidad y de mortalidad (en torno a valores superiores al 50 y al 34/40 por mil, respectivamente) y por las crisis de mortalidad (como la de 1868) durante la cual las defunciones superaron a los nacimientos. Entre las causas de mortalidad se encuentra como factores el impacto de las condiciones climáticas de la campaña (sequías periódicas, como contrapartida épocas de lluvias torrenciales e inundaciones), el efecto negativo ejercido por los malones indígenas, las enfermedades infecciosas como la viruela. ${ }^{5}$ Como sea, esos efectos negativos que provocaron de modo particular una alta tasa de mortalidad infantil, fueron compensados por la tasa de fecundidad. ${ }^{6}$

La presencia de la inmigración —-desde las provincias y desde el aporte europeo con las migraciones «tempranas»- marcó una estructura demográfica «joven» y con predominio masculino. Los pueblos de la campaña bonaerense - no más de una treintena de pequeñas comunidades- en las primeras décadas del siglo XIX contaban con una población que oscilaba entre 500 y 3000 habitantes. Para 1850, algunos de ellos, habían aumentado a 7000 u 8000 pobladores. Por entonces, un $40 \%$ del total de los habitantes de la región serían menores de 14 años. Las altas tasas de mortandad infantil harían suponer que en un pueblo de 1000 habitantes, apenas unos 100 estarían entre los 6 y los 12 años. Fueron recurrentes las migraciones de hombres adultos provenientes de la región interior del país, atraídos por la demanda estacional de mano de obra que se producía con la cosecha estival. Cuando fueron acompañados por sus familias se transformaron en pobladores permanentes.

\footnotetext{
${ }^{4}$ Gladys Massé, «El tamaño y el crecimiento de la población desde la Conquista hasta 1870 » en Población, ambiente y territorio. Tomo 1: Director. Hernán Otero. Colección Historia de la Provincia de Buenos Aires. Director: Juan Manuel Palacio. (Buenos Aires, Editorial Universitaria EDHASA, 2012): 143-172.

${ }^{5}$ Gladys Massé, op. cit, p. 159.

${ }^{6}$ José Luis Moreno y José Matero, «El redescubrimiento de la demografía histórica en la historia económica y social» Anuario IEHS, 12 (997): 23-62.
} 
La mayoría de las familias de la campaña eran nucleares compuestas por los padres y los hijos, incluyéndose a los «entenados», o sea, los hijos habidos en una pareja anterior de uno de los padres. A veces, algún «agregado» o huérfano que tenían una relación lejana con la familia vivía también en la casa. El tipo de viviendas eran diferentes, según las posiciones socioeconómicas que ocupaban sus habitantes. Las casas de los chacareros y labradores, eran bastantes simples, hechas de adobe y paja. Estaban conformadas por la cocina, la sala-comedor, una o dos piezas adyacentes y la «ramada». ${ }^{7}$ Los hacendados, por su parte, tenían casas más confortables. Grandes cocinas donde convivían peones y esclavos; techos de teja y paredes de ladrillos cocidos o de adobe; alguna reja de madera - excepcionalmente de hierro - adornaba dos o tres ventanas sin vidrios. ${ }^{8}$

Los esporádicos registros censales dan cuenta de un dinámico escenario social con crecimiento y migración de sus pobladores. Sin embargo, aquel territorio fue percibido por sus contemporáneos como un mundo carente de civilización signado por la barbarie. En principio, el propio espacio aparecía como una periferia, una frontera y un límite respecto a la civilidad encarnada por la ciudad de Buenos Aires. La frontera era presentada como un escenario de enfrentamientos, violencia y salvajismo. Las incursiones de los malones indígenas, la hostilidad, la guerra, el pillaje, el robo, el contrabando y el crimen signarían la vida de los poblados dominados por indios, vagos, criminales. Ese mundo rural revelaba su atraso al estar solo habitado por estancieros (dueños de la tierra) y la población de los gauchos (algunos conchabados) ${ }^{9}$ y otros perseguidos como vagos y delincuentes.

\footnotetext{
${ }^{7}$ Se llamaba «ramada» 0 «enramada» a un alero en donde generalmente, en las casas campesinas del Interior, estaba el telar de la dueña de casa.

${ }^{8}$ Juan Carlos Garavaglia, «Ámbitos, vínculos y cuerpos. La campaña bonaerense de vieja colonización», en Historia de la vida privada en la Argentina, dirs. Fernando Devoto y Marta Madero Tomo I. (Buenos Aires: Taurus, 1999)

${ }^{9}$ La «papeleta de conchavo» establecía: « $1^{\circ}$ Todo individuo de la Campaña que no tenga la propiedad legítima de que subsistir...será reputado de la clase de sirviente.... $2^{\circ}$ Todo sirviente de la clase que fuere deberá tener una papeleta de su Patrón, visada por el Juez del Partido [...] $4^{\circ}$ Todo individuo de la clase de peón que no conserve este documento será reputado por vago» [...] $6^{\circ}$ Los vagos $[\ldots]$ se destinarán al servicio de las armas por cinco años. Bando de Manuel Oliden, gobernador intendente de Buenos Aires, 1815». Buenos Aires, 30 de agosto de 1815. Archivo General de la Nación, X-2-10-6 (en adelante AGN).
} 
Hubo diferentes valoraciones en las formas de ocupar, habitar, transitar y vivenciar el espacio. Al respecto, los relatos de los viajeros aparecen como testimonios reveladores de la percepción que tenían algunos contemporáneos de aquella realidad social. Su visión europeizante mostraba la sorpresa de encontrarse con la otredad y reforzaba aquella imagen de un territorio sumido en la barbarie y la rusticidad. ${ }^{10}$

Aquellas impresiones condicionaron y, al mismo tiempo, reforzaron la versión de una historiografía tradicional que forjó el mito de la formación de la nación sobre la base de la civilización marcada por el ritmo de la ciudad de Buenos Aires. Pero, la recuperación de la democracia en Argentina durante los años ochenta del siglo Xx, hizo posible complejizar ese paisaje de la campaña bonaerense. Fue posible mostrar una dinámica social y económica donde aparecieron actores claves, como los terratenientes, chacareros arrendatarios, ${ }^{11}$ gauchos que contribuyeron a la exitosa inserción de la región al mercado mundial. A su vez, la expansión agraria promovió la incorporación de tierras y el avance sobre una frontera de contactos intra e interétnicos e incluso intersociales. ${ }^{12}$ Esa frontera estuvo marcada por una larga historia de la llamada «conquista del desierto» por el reparto de la tierra pública, por la expansión horizontal de las actividades económicas en nuevas tierras - la ganadería primero (ovina y vacuna, en ese orden), la agricultura después- y por el progresivo asentamiento de inmigrantes en esas tierras - nacionales primero, extranjeros posteriormente- ${ }^{13}$

Esas transformaciones se dieron en el marco de una sociedad que se regía por la costumbre sustentada en normas implícitas, consensuadas entre las diferentes partes. Esa trama social preexistente chocó contra

\footnotetext{
${ }^{10}$ Mac Cann, Willian [1847], Viaje a caballo por las provincias argentinas. (Buenos Aires: Taurus, 2001)

${ }^{11}$ Se designaba "chacarero» al agricultor que era productor de una chacra — pequeñas parcelas dedicadas a la producción agrícola-. Eran en su mayoría de origen inmigrante y a lo largo del siglo xx - $\mathrm{y}$ fundamentalmente con el peronismo- devino en un «pequeño propietario».

${ }^{12} \mathrm{Al}$ respecto ver, entre otros aportes, sobre el tema: Raúl Mandrini, «Indios y fronteras en el área pampeana (Siglos XVI y XIX). Balance y perspectivas», Anuario IEHS, 7 (1992): 59-72. Carlos Mayo, Vivir en la frontera. La casa, la dieta, la pulpería, la escuela (1770-1870). (Buenos Aires: Biblos, 2002). Sara Ortelli y Silvia Ratto, «Introducción dossier: Poder, conflicto y redes sociales en la frontera pampeana, siglos XVIII-XIX», Trabajos y Comunicaciones, 32/33 (2006):77-85.

${ }^{13}$ Juan Manuel Palacio, La paz del trigo. Cultura legal y sociedad local en el desarrollo agropecuario pampeano, 1890-1945. (Buenos Aires: Edhasa, 2004): 42.
} 
el marco normativo legal que las nuevas autoridades — pertenecientes a la elite urbana ilustrada, por lo general- intentaban construir. En la campaña bonaerense se asistió a una constante tensión entre la ley y las prácticas sociales que regían. ${ }^{14}$

Esa tensión se hizo palmaria en la construcción del orden político de la campaña. En efecto, la consolidación del Estado —en el espacio de la provincia de Buenos Aires- no fue resultado de un proceso lineal sino la conclusión de una dinámica compleja y contradictoria. En este sentido, Juan Carlos Garavaglia plantea la configuración del Estado como la resultante de un "entramado de relaciones sociales de dominación» así como la institucionalización de un poder separado de la sociedad. ${ }^{15}$ Las diversas corrientes que se han dedicado a revisar los procesos de formación del Estado nacional en Latinoamérica, ${ }^{16}$ han mostrado las imbricadas y personalizadas relaciones entre el Estado y sus aparatos legales, militares e ideológicos y los sectores subalternos. La construcción de un aparato público de alcance nacional no fue solo el producto de las luchas con y entre las clases dominantes y las potencias extranjeras, sino de un proceso en el que estuvieron estrechamente vinculados los campesinos, los pequeños propietarios y mucha gente más que conforman lo que genéricamente se los categoriza como subalternos. ${ }^{17}$

La construcción del Estado en la provincia de Buenos Aires - de igual modo que en la nación - transitó por esa cara más cotidiana y negociada

\footnotetext{
${ }^{14} \mathrm{Al}$ respecto ver: Raúl Fradkin, «Cultura jurídica y cultura política: la población rural de Buenos Aires en una época de transición (1780-1830)» en Raúl Fradkin, La ley es tela de araña. Ley, Justicia y Sociedad Rural en Buenos Aires, 1780-1830, (Buenos Aires: Prometeo, 2009), 159-186; Raul Fradkin, «Entre la ley y la práctica: la costumbre en la campaña bonaerense de la primera mitad del siglo XIX», Anuario IEHS, 12 (1997), 141-156.

${ }^{15}$ Juan Carlos Garavaglia, «La apoteosis del Leviatán: el Estado en Buenos Aires durante la mitad del siglo XIX», American Research Review, 38 (1), (2003):135-168.

${ }^{16}$ Un trabajo que resume en su introducción de modo sugerente esas aproximaciones al problema del surgimiento de los Estados nacionales en América Latina es el de: Ernesto Bohoslavsky y Milton Godoy Orellana (eds.), Construcción estatal, orden oligárquico y respuestas sociales: Argentina y Chile, 1840-1930 (Buenos Aires: Prometeo Libros-Universidad Nacional de General Sarmiento, 2010).

${ }^{17}$ Florence Mallon, Peasant and Nation. The making of Postcolonial México and Perú. (Bekerley: University of California Press, 1994). Cabe señalarse que el concepto de subalternidad fue trabajado inicialmente por la teoría social y política de Antonio Gramsci. En los últimos tiempos se puede dar cuenta, gracias a una interesante producción, de dos dominios correspondientes a la política: la política de la «elite» y la política de los «subalternos». En tal sentido, un trabajo de consulta imprescindible es el de: Ranahit Guha, Las voces de la historia y otros estudios subalternos (Barcelona: Editorial Crítica, 2002).
} 
de la relación entre el poder político y las comunidades. A lo largo de la primera mitad del siglo XIX, esas comunidades de la campaña redefinieron la condición de vecindad y la construcción de la ciudadanía. La vecindad y la ciudadanía implicaron conceptos diferentes. La primera, remitía al domicilio y la segunda, al estatuto político, se relacionaba con la prestación de servicios, pago de impuestos y acceso a los bienes de la comunidad lo que exigía una relación constante y directa con la autoridad. Por su parte, la ciudadanía se encontraba sostenida básicamente por la vecindad pero con la Revolución de mayo se dejaron atrás los privilegios que daba el pertenecer al Cabildo por ser vecino. La propia dinámica revolucionaria, y la necesidad de legitimar el nuevo orden, promovió la ampliación de la sociedad política que, acompañada del reconocimiento de la vecindad, se convirtió en el modo cultural y jurídico adecuado para identificar a los incluidos socialmente, exigirles el cumplimiento de la ley y las obligaciones. Aquella búsqueda de la construcción de una nueva legitimidad política hizo posible que transitara de la condición de súbdito a ciudadano. ${ }^{18}$

Finalizada la guerra de independencia comenzaron las luchas internas que promovieron la incorporación de sectores cada vez más amplios de la población a la vida militar y política, en especial, de los sectores subalternos —antes marginados de la vida pública-. La movilización y ampliación de la base política se potenció con la prioridad de construir una nueva forma de gobierno y representación. ${ }^{19}$ La militarización de los subalternos en los ejércitos independentistas y en las milicias amplió las bases de la ciudadanía. ${ }^{20}$ De la mano de ese proceso, se forjan las experiencias del caudillismo y la participación de sus montoneras: los «gauchos». ${ }^{21}$

\footnotetext{
${ }^{18}$ Carlos Cansanello, De súbditos a ciudadanos. Ensayo sobre las libertades en los orígenes republicanos. Buenos Aires, 1810-1852 (Buenos Aires: Imago Mundi, 2003).

${ }^{19}$ Jorge Gelman, «La construcción del orden poscolonial. El «sistema de Rosas» en Buenos Aires entre la coerción y el consenso», Tiempos de América, 11 (2004): 27-44.

${ }^{20}$ Ver: Carlos Cansanello, «Las milicias rurales bonaerenses entre 1820-1830», Cuadernos de Historia Regional, 19 (1998):7-51 y Juan Carlos Garavaglia, «Ejército y milicia: los campesinos bonaerenses y el peso de las exigencias militares, 1810-1860». Anuario IEHS, 18 (2003): 153-187.

${ }^{21}$ Gauchos en sentido amplio podían ser campesinos agricultores, artesanos, peones o incluso -en algunas regiones del interior del país- mineros. Estos hombres formaron las montoneras, fuerza de choque de los caudillos. Un análisis sugerente del caudillismo y la cultura política de los gauchos, es el de: Ariel de la Fuente, Los hijos de Facundo. Caudillos y montoneras durante el proceso de formación del Estado Nacional Argentino (1853-1870) (Prometeo: Buenos Aires, 2007).
} 
El año 1820 significó un punto de inflexión tras la caída del gobierno central. En la ciudad de Buenos Aires y su campaña, asumió el gobierno el Partido del Orden que suprimió el Cabildo, una institución de herencia colonial. ${ }^{22}$ Sancionó la primera ley electoral que planteó el sufragio «universal»—varones residentes mayores de 20 años-, lo cual implicó incluir bajo formas mediatizadas a las poblaciones de la campaña bonaerense. Desde entonces, doce miembros por la ciudad y once por la campaña integraron la Junta de Representantes, encargada, entre otras cosas, de legislar y nombrar a los gobiernos provinciales de turno. Además, cerró los Cabildos, sustituyó a los Alcaldes de Hermandad por los Jueces de Paz. Estos nuevos funcionarios fueron elegidos dentro del grupo de vecinos respetables de la comunidad, con la intención de que actuaran como mediadores en conflictos de rango menor. Tiempo después, y luego de un nuevo enfrentamiento entre facciones unitarias y federales, durante el primer gobierno Juan Manuel de Rosas terminaron por convertirse en referentes del aparato coercitivo, administrativo y judicial de la campaña.

También se pensó en imponer una justicia letrada en la campaña a cargo de cinco Juzgados de primera instancia y organizar una estructura de ocho comisarías de policía dependientes directamente del gobierno. Pero esta organización tuvo corta duración. En 1824, se redujo los cinco juzgados a cuatro (dos civiles y dos criminales), todos localizados en la ciudad. Transitoriamente se anularon las comisarías de campaña, trasladándose sus funciones a los Jueces de Paz y se dispuso que, cada uno, tuviera una partida de tres milicianos con remuneración. En julio de 1825, se ordenó la reposición de las ocho comisarías y, a fin de ese año, se autorizaron dos nuevas. ${ }^{23}$

Más allá de ese avance secular, otro referente de orden para los pobladores fue el cura parroquial. La estructura de poder eclesiástica mantuvo en sus manos algunos mecanismos importantes de control social en el plano local. Los curas cumplieron funciones decisivas para el ejercicio

\footnotetext{
${ }^{22}$ Gabriel di Meglio, ;Viva el bajo pueblo! La plebe urbana de Buenos Aires y la política entre la Revolución de Mayo y el rosismo (Buenos Aires: Prometeo, 2007).

${ }^{23}$ Cuando llegó al poder Juan Manuel de Rosas, en 1830, se elevó de 10 a 21 las secciones de policía y, en 1836, transfirió las funciones y la renta de los comisarios a los Jueces de Paz.
} 
de ese poder en cada localidad. De hecho, las figuras del juez de paz y el cura fueron cada vez más complementarias. ${ }^{24}$

Por su parte, la estructura militar y miliciana en la campaña tuvo como sedes principales a los fuertes y fortines de la frontera, pero estuvo también presente en otros pueblos con destacamentos que no tenían una localización fija y estable. Si bien con dificultades en el cumplimiento de sus funciones, existió una fuerza de ejército regular en puntos decisivos de la campaña, pero había también posibilidad de movilizar cuando era necesario a milicianos, entre ellos contingentes indígenas. La crisis revolucionaria puso en primer plano la necesidad de conformar un poder de policía más efectivo, que dependiera directamente del poder central.

Las autoridades recurrieron a diversos mecanizamos para forzar la activa colaboración de los vecinos del pueblo. Así, funcionaron partidas estables y remuneradas y otras extraordinarias y ocasionales, que implicaban la movilización de los vecinos cumpliendo la función de celadores o serenos. El intento de separar las funciones judiciales y policiales a nivel local fue infructuoso, a pesar de que se buscó que los Jueces de Paz fueran parte de la comunidad de legos, designados por partido y sin remuneración mientras que, los comisarios pueden ser vistos como el embrión de una burocracia estatal rural ya que eran rentados. Con el tiempo, la solución de fusionar ambos tipos de poderes, se puede entender como una búsqueda de centralizar el control, asentado en una base de poderes locales socialmente construidos lo que convirtió a los jueces en personal remunerado, dotado de subalternos y de una partida armada.

Cuando llega al gobierno de Buenos Aires el caudillo Juan Manuel de Rosas, se impuso la dominación de la Federación al resto de las provincias y, con ello, una fuerte militarización de los sectores populares. A grandes rasgos, suelen existir dos posturas en torno al régimen rosista. Para sus detractores, fue un gobernador despótico que instauro un régimen de terror y obstaculizó el orden constitucional mientras que, para sus defensores, fue un líder aclamado por los sectores populares

${ }^{24}$ Durante los tiempos del primer (1829-1832) y segundo gobierno de Rosas (1839-1852), se les asignó a los párrocos precisas funciones de control del orden local en las zonas más antiguas de asentamiento demográfico mientras que, en las nuevas zonas incorporadas la columna vertebral del estado provincial sería de poder militar y miliciano. Cfr.: María Inés Barral, De sotanas por la Pampa. Religión y Sociedad en el Buenos Aires rural tardocolonial (Buenos Aires: Prometeo, 2007). 
que pacificó el país antes de organizarlo constitucionalmente y defendió la soberanía nacional frente a las potencias europeas. Tras su derrota, quedó pendiente la construcción de una nueva legitimidad política que se consagró con la sanción de la Constitución nacional de 1853, estableciendo la organización republicana, representativa y federal de gobierno. Quienes elaboraron el nuevo proyecto de país entendían que el pueblo no estaba preparado para la democracia. Tal como lo proclamó Juan Bautista Alberdi, había que transitar de la república posible a la república verdadera. Más allá de esa aspiración de la elite dirigente, aquella campaña bonaerense con sus prácticas socio-culturales — percibida como lo rústico- fue activa partícipe de esa construcción con sus propios referentes, con su capacidad de resistencia y de negociación. ${ }^{25}$ En el marco de ese entramado político-social, se radicaron las primeras escuelas elementales en la ciudad y la campaña, estimadas como pilares para la configuración del nuevo orden republicano. Sin embargo, más allá de ese acuerdo compartido, quedaron expuestas las disputas y tensiones protagonizadas por los distintos actores de ese escenario social. ${ }^{26}$

\section{VECINOS, ESCUELAS Y PRECEPTORES EN LA CARTOGRAFÍA SOCIAL DE LA CAMPAÑA BONAERENSE}

Para las emergentes repúblicas nacionales latinoamericanas, la instrucción pública era el instrumento con el que se podía emprender la monumental empresa de transformar a los súbitos del antiguo orden colonial en ciudadanos libres e iguales. ${ }^{27}$ Eso llevó a cuestionar el monopolio que había mantenido la Iglesia católica en la educación y formación de la infancia, planteando un nuevo modelo de escolarización que erradicara, en términos de Sarmiento, los lastres de una barbarie que encontraba sus raíces en el pasado colonial.

\footnotetext{
${ }^{25}$ Un sugerente aporte en ese sentido, a partir del análisis de la justicia criminal es el de: Melina Yangilevich y Eduardo Míguez, « Justicia criminal y Estado en la frontera de Buenos Aires, 1852-1880», Boletín del Instituto de Historia Argentina y Americana «Dr. Emilio Ravignani», 32 (2010): 107-130.

${ }^{26}$ Un trabajo que, desde una perspectiva regional comparada, analiza de modo exhaustivo el lazo entre escuelas y política a los efectos de problematizar los procesos de construcción estatal es el de: José Bustamante Vismara, "Construcción estatal y desarrollo escolar (Córdoba, Buenos Aires y Entre Ríos), 1820-1850» en Historia de la Educación, Anuario SAHE (Argentina), Vol.17-N. ${ }^{\circ} 1$ (2016): 50-71.

${ }^{27}$ Mónica Quijada, «Sobre «nación», "pueblo», "soberanía» y otros ejes de la modernidad en el mundo hispánico». en Las nuevas naciones. España y México, 1800-1850, ed. en Jaime E. Rodríguez (Madrid: Mapfre Editores, 2008), 19-51.
} 
En el caso del Río de la Plata, más allá de las continuidades en materia de instrucción pública entre la etapa colonial y los tiempos de la revolución, se advierte el temprano interés de las autoridades de la Junta de gobierno por garantizar la escolarización de la niñez con nuevas implicancias patrióticas. ${ }^{28}$ Por los rasgos de esa sociedad, se parte del presupuesto que, tanto las escuelas elementales como sus improvisados preceptores, devinieron en una difusa referencia de esa estatalidad en plena configuración. Como muestran las fuentes consultadas, los distintos actores estatales que participaron de modo directo o indirecto en ese proceso escolarización entablaron acuerdos pero también cruces y disputas de diverso tenor con los referentes de las comunidades. Sin embargo, esas situaciones no fueron en desmedro en la voluntad compartida de extender el brazo civilizador de la instrucción pública.

En los primeros tiempos del gobierno independentista, la prensa - comprometida con el ideario revolucionario- impulsó desde sus páginas la idea de que era preciso difundir las luces de la instrucción con el objeto de formar a un ciudadano "virtuoso e ilustrado» sobre el que se cimentaría el nuevo orden. Según se argumentaba: «[...] El país se halla en una infancia general en todo sentido y en la necesidad de aspirar a todo tipo de gloria [...] en fin esforzarse por ser contado entre los pueblos cultos e ilustrados que honran tanto a la especie humana». ${ }^{29}$ Con una suerte de euforia se afirmaba que, "[...] bastaban veinte años para regenerar [...] si se enseñase gratuitamente a todos los niños y jóvenes pobres lo que es útil y necesario a la sociedad, adaptándose a métodos de enseñanza fáciles y sencillos». ${ }^{30}$ Para ello, «la formación no debía limitarse a instruir, sino a despertar en el corazón sentimientos útiles, elevados, patrióticos por lo cual se estimaba que, lo más adecuado era introducir el método Bell y Lancaster», un método

\footnotetext{
${ }^{28}$ Sobre la escolarización en Buenos Aires y su campaña existen pocos trabajos de los que podemos mencionar: Carlos Newland, « La educación elemental en Hispanoamérica: desde la independencia hasta la centralización de los sistemas educativos nacionales», The Hispanic American Historical Review, 71 (2) (1992): 335-364; José Bustamante Vismara, Las escuelas de primeras letras en la campaña de Buenos Aires (1800-1860). (La Plata: Asociación Amigos del Archivo Histórico, 2007); Lucía Lionetti, «Las escuelas de primeras letras en el escenario social de la campaña bonaerense (1850-1875) »en Naveg@merica. Revista Española de la Asociación de Española de Americanistas Universidad de Murcia (España), Vol. 4 (2010).

${ }^{29}$ Biblioteca Nacional: El Censor, n. ${ }^{\circ} 80,27 / 03 / 1817$. En adelante: El Censor

${ }^{30}$ El Censor: n. ${ }^{\circ} 115,27 / 11 / 1817$.
} 
que parecía "sencillo y ventajoso". ${ }^{31}$ Una renovación que no encontró eco favorable entre los maestros, tal como reflejaba la propia prensa comentando:

[...] los maestros sostienen su antiguo método, y sin atender razones se oponen a la novedad sea la que fuera, por no tener el trabajo de aprender para enseñar con más fruto [...] alegan un pretexto muy especioso cual es el de la religión. [...] su miedo es infundado [...] El hereje quacaro (sic) Lancaster expresamente dice que él no es el inventor [...] él sabía que su método era invención de los católicos $[\ldots] .^{32}$

Por su parte, el Gobernador Intendente de la campaña bonaerense - Manuel Luis Oliden- también hizo notorios esfuerzos por extender la instrucción pública. Las pocas escuelas que consiguió que se crearan, en el marco de las guerras por la Independencia, se solventaron con el impuesto por la venta de ganado y de pan. Otra iniciativa fue la de promover la redacción de un reglamento - redactado por los preceptores Rufino Sánchez y Francisco Javier Argerich- en el que se dispuso que, los patronos de las escuelas deberían ser los santos mártires San Justo y Pastor para que sus virtudes sirvieran de ejemplo a los niños y que, los preceptores debían acceder al cargo mediante un concurso de oposición, prefiriéndose - entre las condiciones que debían reunir - que fuera residente del mismo partido en el que cumpliera las funciones como educador. Se recomendaba, además, que los preceptores tratarán con liberalidad y amor a sus discípulos de quienes exigiría respeto y obediencia. Respecto a las clases, se reglamentó que fueran de dos turnos, fijando los contenidos, gradación de la enseñanza y procedimientos didácticos. Se prescribieron las clases públicas bimestrales y se impuso la obligación escolar encomendando a los Alcaldes y a los curas para que la hicieran "cumplir con todo rigor de la justicia». ${ }^{33}$

En función de las tareas rurales se fijaron las vacaciones desde el 8 de enero hasta el primer lunes de la cuaresma. Se crearon las Juntas Protectoras de las escuelas de campaña de cada partido, integradas por el

\footnotetext{
${ }^{31}$ El Censor: $.^{\circ} 82,9 / 4 / 1817$.

32 Biblioteca Nacional: La Matrona Comentadora de los Cuatro Periodistas, 1821, s/f.

${ }^{33}$ Archivo General de la Nación, Sala X, Gobierno, S5, C12, Al, N. ${ }^{\circ}$ 6, 1815. En adelante: AGN.
} 
Alcalde de Hermandad, el Cura o su Teniente y un vecino de "probidad». Entre sus funciones, debían inspeccionar las escuelas, recaudar fondos para su sostenimiento, disponer que los vecinos pudientes mantuvieran uno o dos niños que por su pobreza y la distancia no pudieran concurrir a las escuelas desde sus domicilios. El sueldo de los preceptores sería abonado por la Intendencia de Policía.

Para el año 1817, se designó al canónigo Dr. Saturnino Segurola como primer Director General de Escuelas, cargo que ocupó con breves períodos de interrupción hasta 1852. En ese año, se estableció un nuevo reglamento con ligeros cambios respecto al anterior. En particular, se hizo un especial hincapié en que los «[...] maestros procuraran no ultrajar a los niños con dicterios indecentes, ni estropearlos con golpes [...]». De manera contradictoria, se pautó que: «[...] Sería reprensible [que] cualquier niño echare en cara alguna falta en el linaje a otro igual», al tiempo de determinarse que, «Los niños decentes no se mesclaran (sic) con los debajo color, como negro o mulato».

A lo largo de estos años, en esta instrucción elemental, la enseñanza religiosa ocupó un lugar preeminente basada en el catecismo de Astete (o en su lugar de Ripalda) y el de Fleury, ambos utilizados en la etapa colonial. El rasgo novedoso de aquella instrucción lo dio esa impronta patriótica que se le buscó dar cuando, a partir de 1812, se reglamentó el uso de la escarapela y la conmemoración de fechas patrias. Otra novedad fue la que dispuso la Asamblea del Año XIII, con la supresión del castigo por azotes.

Con la crisis del año 1820, tras la caída del gobierno central y el advenimiento de los gobiernos autónomos provinciales, la ciudad de Buenos Aires y la campaña fue gobernada por el Partido del Orden: Entre las diversas iniciativas que promovió el nuevo gobierno, se suprimió el Cabildo con lo cual las escuelas de primeras letras, por un breve período, quedaron supeditada a la figura del Director de Escuelas. Posteriormente, se incorporaron a la Universidad de Buenos Aires. Otra medida, del emblemático y discutido ministro de gobierno Bernardino Rivadavia, fue ceder la administración de las escuelas públicas de niñas y del Colegio de Huérfanos - anteriormente controlado por la extinguida Hermandad de 
Caridad- a la Sociedad de las Damas de la Beneficencia. ${ }^{34}$ El objetivo de estas reformas fue la de terminar drásticamente con la herencia de la estructura colonial y modernizar las prácticas sociales y el imaginario político. Es decir, establecer una cultura política afín a las nuevas concepciones ilustradas y liberales de la época. Este plan reformista también buscó conformar un tipo de ciudadano basado en una matriz republicana-ilustrada, para lo cual se fomentó la introducción del sistema lancasteriano en las escuelas primarias y la creación de la Universidad en el ámbito de los estudios superiores. Así, mientras que una de las funciones centrales de la educación de Primeras Letras fue incrementar la presencia del Estado en la campaña a través de la instalación de escuelas, la Universidad buscó modificar la matriz escolástica tomista en pos de educar a las élites en una clave republicana acorde a los lineamientos del elenco dirigente.

En la práctica, el nuevo Director General de Escuelas, el español Pablo Baladía - también a cargo de la Normal de la Universidadencontró escollos a la hora de promover la capacitación de los preceptores en el promocionado sistema de enseñanza mutua. La resistencia de los preceptores a asistir a la Normal dificultó que el método pudiera implementarse con la eficacia que pretendían las autoridades. ${ }^{35}$

Por su parte, en la campaña bonaerense, se removieron las Juntas Protectoras por Juntas Inspectoras conformadas por el Juez de Paz y dos «vecinos respetables» del lugar. Si bien los curas párrocos quedaron fuera de esa función, en un evidente guiño de la impronta liberal del momento, las autoridades y vecinos notables requirieron de su colaboración por su llegada a la comunidad.

La realidad social de la vida en la campaña puso un límite a esas iniciativas. A la lábil presencia de las autoridades estatales y los problemas de la escuela elemental, se le sumaron frecuentes situaciones de conflicto entre los diversos personajes de la comunidad. Un caso ilustra en ese sentido acaecido en el año 1824, cuando desde el gobierno de Bueno Ai-

\footnotetext{
${ }^{34}$ Archivo Histórico de la Provincia de Buenos Aires: Registro Nacional, libro 2. Recopilación de leyes $y$ decretos (1810-1835), p.7772. En adelante: AHPBA: Registro Nacional.

${ }^{35} \mathrm{Al}$ respecto se dispuso en un decreto -inspirado en la propuesta de Baladía-, entre otras cuestiones que: «1. ${ }^{\circ}$ : Todo el que solicitase regentear algunos de los establecimientos de primeras letras, deberá acreditar previamente su moralidad e inteligencia en el sistema de enseñanza mutua. $2 .^{\circ}: \mathrm{La}$ moralidad se justificará ante el Vice-Rector Inspector de escuelas, la inteligencia en el sistema de enseñanza mutua ante el Director General de dichas escuelas [...]». AHPBA: Registro Nacional, 796.
} 
res, se impulsó una serie de medidas de gobierno en materia educativa. Exactamente en la comunidad de Morón en el año 1824, los registros documentales nos permiten reconstruir un conflicto entre la Junta Celadora (conformada por vecinos notables) y el Preceptor nombrado por las autoridades. La conflictiva relación del Preceptor con aquellos vecinos se hizo evidente cuando los miembros de la Junta le exigieron que presentara las instrucciones que tenía respecto a la utilización del sistema de Lancaster. Con cierta sorna y tono altanero el Preceptor envió una nota de respuesta donde les dice que desconocía el sistema que ellos llamaban Lalcaster (sic) pero que si conocía las instrucciones del Sr. Bell y el Señor Lancaster y que " [...] si querían proveerse de un ejemplar se los acercaría puesto que el Superior Gobierno las tiene puesta a venia pública en la Biblioteca de la Universidad por el precio de un peso». La respuesta de la Junta exigió más moderación en su modo de expresarse. El conflicto llegó hasta la autoridad responsable de las escuelas de primeras letras, el Rector de la Universidad de Buenos Aires. Precisamente el Rector, Antonio Sáenz, al informar al Ministro de Gobierno, Manuel García, comenta entre otros términos:

[...] El Cura de Morón [...] se había empeñado en tratar al Preceptor como si fuera su Sacristán y en llevarse a los Niños de la Escuela a sus Misas cantadas para que se las sirviesen con prejuicio de la enseñanza [...]. Comenzó de repente a titularse Presidente de la Junta Celadora cuando en Morón nunca se ha establecido tal Junta y tan solo por mi parte que fui a la visita de Escuelas le hice la prevención de palabra para que él y el Juez de Paz estubiesen a la mira de la conducta de los Preceptores y me avisasen si faltasen a sus obligaciones. Este es el hombre quien de improviso [...] abusando del cambio de Juez de Paz se levanta con la autoridad de intimar ordenes (sic) al Preceptor de la Escuela y quieren obrar con independencia mía. El convoco al vecindario, le hizo elegir con otros para la Junta Celadora y me han pasado oficios haciéndome requerimientos tan groseros, tan desvergonzados y atrevidos [...]. Todo me parece que queda remediado con que el Preceptor se arregle con lo que tiene mandado y el Cura no tome parte en la dirección de la Escuela, pues que 
para el nuevo reglamento la Junta Inspectora solo se deba componer del Juez de Paz y dos vecinos. ${ }^{36}$

La Junta responde que fue impuesta por los Padres de varios niños y que el Maestro, infligiendo el mandato de Gobierno que prohíbe todo castigo aflictivo e ignominioso, violentó a sus alumnos,

[...] estropeando [sus manos] azotándolos con disciplina (aunque sobre las ropas) pero de un modo torpe, poniéndolos en el patio de la Escuela a la expectación de los que pasan por la plaza y autorizando a los demás niños a que hagan toda especie a befa a los que han sufrido aquel castigo. [...] lejos de estimular en los niños las pasiones nobles [...] solo haga que pierdan el pudor y se formen entre ellos odios y enemistades [...]. ${ }^{37}$

La respuesta del Rector fue contundente al sostener que los más perjudicados eran los vecinos, por lo difícil de encontrar maestros de buenas cualidades que quisieran establecerse en el campo y, más aún, si eran molestados por el Juez y el Cura Párroco. ${ }^{38}$ La máxima autoridad finalmente decide que, el Rector de la Universidad, aperciba seriamente al Maestro por su conducta irregular y falta de respeto a los miembros de la Junta Inspectora y que, en lo sucesivo, se aplique los castigos que correspondientes si no utiliza el sistema de Lancaster. La autoridad de Buenos Aires no pudo desconocer el malestar de los referentes de aquella comunidad.

Las denuncias contra los preceptores fueron reiteradas. Así lo hizo la junta inspectora de la escuela de primeras letras del Fortín de Navarro quien manifestó la urgente necesidad de destituir de su preceptoría a Don Ramon Grimard por «[...] ser notoriamente ebrio, abandonando, inepto y aun malversador de los útiles confiados a su administración a beneficio de los hijos de Padres destituidos de recursos». ${ }^{39}$ Según se aduce, su inmoralidad y faltas notables habrían escandalizado a los padres de familia. Se continuaba aduciendo que, hasta el Teniente Cura al examinar la escuela habría encontrado al Preceptor caído por la embriaguez en presencia de

\footnotetext{
${ }^{36}$ AGN: Sala X 6-1-2, 1824.

${ }^{37}$ AGN: Sala X 6-1-2, 1824.

${ }^{38}$ AGN: Sala X, 5-1-2, 1824

${ }^{39}$ AGN: Sala X, 6-1-2, 1826
} 
los discípulos, razón por la que hizo llamar al Juez quien lo amonestó. Sin embargo, sus faltas se reiteraron incluso en una reunión en su casa con sus amigos, a quienes habría molestado a punto de «[...] que lo tomasen, lo pusiesen sobre la mesa, le bajasen los calzones y la pusiesen de manifiesto la vergüenza y su esposa abochornada de las cosas que su marido daba lugar hiciesen con él, le obligó a irse a la Capital [...]». ${ }^{40}$

Hacia fines de 1827, debido a las diversas situaciones conflictivas generadas - sobre todo con la fuerte oposición de los preceptores a la figura del español Baladía - se dispuso la separación de la Universidad del Departamento de Escuelas de Primeras Letras. Al año siguiente, se designó nuevamente a Saturnino Segurola como Inspector General. Más allá de esos ingentes esfuerzos, y pasado el breve intento de centralización que llevó a la presidencia al liberal Bernardino Rivadavia, las nuevas autoridades de Buenos Aires - en su balance sobre el estado de la escolarización- reconocieron que los mayores logros en la educación los había conseguido la Sociedad de Beneficencia.

Sin embargo, más allá de ese reconocimiento la tarea de la Sociedad de Beneficencia fue ardua y tuvo también serios inconvenientes, sobre todo por diversas situaciones conflictivas libradas con las Rectoras designadas y por no contar con maestras capacitadas. Las discusiones entre las socias iban desde las dificultades económicas a la necesidad de cumplir con el requisito de que hubiera dos maestras por cada curso. Inclusive alguna de ellas se pronunció favor de «[...] tomarse un buen maestro que enseñara con perfección á escribir y contar». ${ }^{41}$ Más allá de esas dificultades ${ }^{42}$, tuvieron la intención de proporcionarles a las niñas la mejor educación. Incluso, hicieron ingentes esfuerzos por poder contem-

\footnotetext{
${ }^{40}$ AGN: Sala X, 6-1-2, 1826.

${ }^{41}$ AGN, SB-LA N. ${ }^{\circ}$ 1, Acta 33 del 18 de octubre de1826. Citado por: María Cristina Jojot, «La Sociedad de Beneficencia de Buenos Aires. Conversaciones, administración y tutela en los años fundacionales 1823-1835», Tesis de Maestría, Universidad de San Andrés (2017): 75.

${ }^{42}$ Uno de los casos que nos interesa seguir explorando, fue el que tuvieron que afrontar las damas -que llevara a la renuncia de su entonces presidenta, Mariquita Sánchez de Mendeville- por la muerte de una niña, supuestamente a raíz del castigo que le propinó su maestra. Un año después, y ante la persistencia de la madre que pudo contar con el apoyo de los vecinos, las damas la citaron para que expusiera su denuncia antes de que el caso llegara a las autoridades. Ver: AGN, SB, LA N. ${ }^{\circ} 2$, Actas de 8 de noviembre y 5 de diciembre de 1831. La cuestión del castigo físico en las escuelas ha sido trabajado en: Lucía Lionetti, «Cuerpo y castigo. La penalidad física en las escuelas elementales de Buenos Aires y la campaña en el siglo XIX», Quinto Sol, Vol. 19, (2) (2015): 1-21.
} 
plar todas las solicitudes que formulaban madres, padres o ambos para que sus hijas pudieran ingresar como internas. La falta de presupuesto era un inconveniente con el que tuvieron que lidiar año tras año, sin embargo, los gobernadores de turno -incluso aquellos con los que tuvieron enfrentamientos políticos- no dejaron de reconocer su labor. Un gesto que, sin duda, estuvo relacionado con la impronta que estas mujeres tenían dentro de la elite gobernante.

Los logros alcanzados en aquellos años encontraron un punto de quiebre con el gobierno en la provincia del caudillo federal Juan Manuel de Rosas, quien decretó el cierre virtual de las escuelas y el desmembramiento de la Universidad de Buenos Aires, aduciendo que no se podía abonar los sueldos. Durante su dos gestiones (1829-1832 y 1835-1852), la enseñanza particular, que se había mantenido con regularidad y sin mayores exigencias y controles por parte de las autoridades públicas, estuvo en el foco de atención. Se determinó que, en adelante, - conforme a la moral de la Iglesia Católica Apostólica Romana-, deberían contar con la autorización del Inspector General para su funcionamiento dentro del territorio de la provincia previa «justificaciones necesarias sobre la moralidad, religión y suficiencia». ${ }^{43}$ Tal como se pautó, las escuelas de primeras letras que continuaran funcionando debían no solo difundir conocimientos básicos de lectura, escritura y de religión sino que, debían mostrar la adhesión a la causa del régimen, determinado que:

[...] se prevenga al Inspector General de Escuelas Publicas, que siendo Divisa punzo que llevan en el pecho los amigos del orden y restauradores de las leyes un distintivo a su adhesión a la causa de los Libres, que hace extensible su oposición a los tiranos, que bajo el pretexto al régimen de unidad pretenden subyugar los Pueblos [...] ha acordado el Gno. (sic) que deben usar no solo todos sus empleados de su dependencia, sino que también deberán propender a que los discípulos lo usen [...] [para] inspirarles amor y respeto a las leyes de su Patria, que no es dado a nadie violar impunemente.[...]. ${ }^{44}$

${ }^{43}$ AGN: Sala X-17-6-3, 1832.

${ }^{44}$ AGN, Sala X-17-6-3, 1832. 
Nuevamente se dejó como única fuente de financiamiento para las escuelas de la campaña los ingresos obtenidos de los corrales de abasto. Además, se decretó que no se debía exigir a los padres indigentes que sus hijos cumplieran con la instrucción escolar. Los fondos públicos se destinaron principalmente al mantenimiento de los gastos militares - producto de la urgencia que marcaba el estado de guerra que se vivía- y para el clero que debía difundir el sermón patriótico-federal. Esa restricción de fondos ${ }^{45}$ implicó que las escuelas de la campaña -incluso las escuelas de niñas que estaban bajo la gestión de las Damas de la Sociedad de Beneficencia- quedaran libradas a los esfuerzos de los pobladores. Además, se otorgó el contralor de las escuelas y de su personal docente al Jefe de Policía, reduciendo claramente la injerencia del Inspector de Escuelas.

\section{HACIA LA CONFIGURACIÓN DE UN SISTEMA PÚBLICO DE EDUCACIÓN. ENTRE EL ESFUERZO CENTRALIZADOR DEL ESTADO, LA RESISTENCIA Y LA NEGOCIACIÓN CON LOS REFERENTES DE LA COMUNIDAD}

Tras la caída de Juan Manuel de Rosas, en 1854, se sancionó en la provincia la Constitución provincial y la ley orgánica de municipalidades y, en 1865, se redactó el Código Rural, con el que se pretendió mejorar la definición de los derechos de propiedad y superar las prácticas consuetudinarias de los vecinos. En ese contexto, el estado provincial hizo mayores esfuerzos por retomar la centralidad en la administración de la escolarización. Como parte de ese proceso organizador, se procedió a la creación del Consejo de Instrucción Pública para la dirección de la enseñanza primaria y los estudios superiores bajo la presidencia del Rector de la Universidad de Buenos Aires. Una de las primeras medidas de ese organismo fue disponer que, en cada localidad, se formara una comisión de tres vecinos «respetables» para que levantaran suscripciones para la fundación de escuelas. En virtud de la importancia de las tareas que exigiría el desarrollo de las escuelas comunes, se creó el Departamento de Escuelas, designándose a Sarmiento, durante el gobierno de Obligado y siendo ministro Vélez Sarsfield, en junio de 1856. En el marco de su primer ejercicio como Director del Departamento de Escuelas, consiguió

\footnotetext{
${ }^{45}$ AHPBA, Registro Oficial. Libro 4. Recopilación de leyes y decretos 1810-1835, 12 junio 1835.
} 
que se sancionara la Ley de fondos propios para el funcionamiento de las escuelas en 1858. ${ }^{46}$ También en ese año comienza a publicarse los Anales de la Educación Común, con la intención de llegar a la opinión pública promoviendo los beneficios de la educación y, de modo particular, de un modelo de escolarización pública.

Tal como sostuvo, quien fuera considerado el promotor de la escuela pública en Argentina, el mandato civilizador de la educación sería el de erradicar definitivamente la «ruralización de la política», en clara referencia a lo que consideraba como la experiencia del caudillismo rosista. Fue una etapa donde las fuentes de conflicto se renovaron, más allá de la convicción compartida de extender la alfabetización. Así, por ejemplo, a pesar de la intención de Sarmiento de fomentar la instrucción laica, los curas continuaron con su injerencia en materia educativa. Fueron parte de ese conjunto de personajes de los pueblos de la campaña con reconocimiento público convocados para formar parte de las comisiones municipales de educación, de las comisiones evaluadoras o enseñando la doctrina religiosa en las escuelas. ${ }^{47}$ La lábil presencia de los gobiernos nacionales y provinciales de los años anteriores había contribuido a reforzar las prácticas comunales que permitieron la acción de los personajes «notables». ${ }^{48}$ De allí que, molestara la impronta de la gestión de Sarmiento, inspirado en las renovadas propuestas pedagógicas de Horace y Mary Mann que lo llevaron —incluso - a traer maestras normalistas norteamericanas para formar al nuevo elenco del magisterio.

\footnotetext{
${ }^{46}$ Sobre la preocupación de Sarmiento de solventar con rentas propias a la educación ha sido trabajada por: Fernando Barba, «Un aspecto poco conocido del ideario de Sarmiento. El desarrollo educativo basado en la creación de rentas propias a la educación pública» en Anales $N .^{\circ} 41$, Facultad de Cs. Jurídicas y Sociales (2011): 4-13.

${ }^{47}$ En aquellos años llegan al país numerosas congregaciones religiosas provenientes de Europa que fundan colegios y hospitales. Ver: Loris Zanatta y Roberto Di Stefano: Historia de la Iglesia Argentina. Desde la Conquista hasta fines del siglo XX (Buenos Aires: Grijalbo, 2000). Un trabajo que recupera esa presencia de los curas en las comunidades de la campaña bonaerense en la segunda mitad del siglo XIX es el de: Lucas Bilbao, «Gringos» en la frontera: los curas del Tandil y el Azul en la segunda mitad del siglo XIX», Revista Folia Histórica del Nordeste, Instituto de Investigaciones Geohistóricas (Conicet-UNNE) e Instituto de Historia, Facultad de Humanidades (UNNE).

${ }^{48}$ Un trabajo muy sugerente que recoge la trayectoria del inmigrante danés Juan Fugl en materia educativa en Tandil (sudeste de la provincia de Buenos Aires), que contó con ciertas ventajas comparativas en un contexto signado por el analfabetismo, es el de: María Mónica Bjerg, El mundo de Dorotea. La vida en un pueblo de la frontera de Buenos Aires en el Siglo XIX, (Buenos Aires: Imago Mundi, 2004).
} 
Esa intención de promover la renovación pedagógica abrió otro frente de tensión con las Damas de la Sociedad de las Beneficencia y sus métodos de enseñanza. Una de las más críticas con el tipo de enseñanza que recibían las niñas en esas escuelas fue la maestra Juana Manso. ${ }^{49}$ Como argumentaba, aquella educación básica estaría preñada de confesionalidad en su hacer. Por cierto, sus dichos no estaban tan alejados de las críticas que las propias inspectoras de la Sociedad solían registrar al supervisar el funcionamiento de las escuelas de la campaña, donde revelaban situaciones de irregularidad y datos poco alentadores sobre el nivel de instrucción. ${ }^{50}$

Fue Mariquita Sánchez de Mendeville, la que directamente interpeló a su antiguo aliado de la causa anti-rosista. En una carta personal a Sarmiento, respondió a la impugnación de la que era objeto la labor de la Sociedad de Beneficencia, expresando:

Qué mala partida me ha hecho el viejo amigo con ese negro informe contra esta pobre Sociedad! [...] Mis compañeras están sentidas en alto grado; pero yo tengo más filosofía y aquí tiene la prueba. Ud nos acrimina porque no hacemos innovaciones $\mathrm{y}$, entre tanto, con todas sus evoluciones, nos da Ud. el resultado más triste de su Escuela Modelo que no ha quedado fijo sino un discípulo! Es preciosa su ingenuidad, pues a nosotras no se nos van $[\ldots]$ lo he desconocido en este informe porque en sus ideas de progreso su empeño es destruir nuestra corporación, olvidando su decreto de instalación, tan sublime, y en una tierra en que

\footnotetext{
${ }^{49}$ La Manso estuvo exiliada junto con su familia durante el primer gobierno de Rosas y en Montevideo hizo sus primeras armas en la docencia. En Río de Janeiro, donde se trasladó y se casó posteriormente, colaboró en el Jornal das Senohas. Cuando regresó a Buenos Aires fue nombrada por Sarmiento maestra y directora de una escuela. A través de su periódico Album de Señoritas, fundado en 1854, planteó la necesidad de promover la educación integral para la mujer por considerar que «su falta de educación generaba su opresión en el hogar perjudicando a la nación toda». Después de Sarmiento fue la directora de los Anales de la Educación.

${ }^{50}$ Ver: Fundación de Escuelas Públicas en la Provincia de Buenos Aires durante el gobierno escolar de Sarmiento 1856-1861/1875-1881. La Plata: Taller de Impresiones Gráficas, 1939. No resulta extraño, por otra parte, que se hablara de atraso en la enseñanza teniendo en cuenta que muchas de las preceptoras no tenían formación en el ejercicio del magisterio, acreditando solo su moral y buenas costumbres, nociones de lectura y escritura, aritmética y de la doctrina católica. Por una cuestión de espacio no podemos extendernos más sobre la radicación de escuelas de la Sociedad de Beneficencia en la campaña. Al respecto consultar: Lucía Lionetti, «Las Damas de la Sociedad de Beneficencia educan a las hijas de la campaña bonaerense (1852-1875) » en: Flavia Werle, La educación rural en América Latina siglo XIX y XX. Editorial Liber Libros (Brasil, 2010):172-195.
} 
los hombres están siempre en guerra civil [...] Vaya, mi amigo, que ha delirado en ese informe. ${ }^{51}$

Por otra parte, continuaron las denuncias por escuelas que se cerraban o no funcionaban por falta de presupuesto así como también, las quejas de los preceptores por conciliar el ritmo escolar con el ritmo de trabajo de los niños en el campo. Además de los meses de verano y cosecha, durante el resto del año las actividades rutinarias ocasionaron inasistencias más o menos recurrentes a las clases. Los dichos de uno de aquellos preceptores resultan reveladores cuando informaba a las autoridades que:

Entre los niños que concurren a estas Escuelas, muchos tienen que hacer hasta dos leguas, por lo cual les es imposible estar presente a las 10 en la Escuela. Esta misma razón de distancia es la que nos obliga a cerrar las aulas más temprano los sábados [...] De todo esto resulta que solo 28 horas funcionan las Escuelas en lugar de $33 \mathrm{~h}$. como les corresponde. Sin embargo solo se pierde 3 horas de enseñanza en las materias; pues hemos creído más prudente disminuir más bien las horas de recreo que no las de clases $\left[\ldots . .{ }^{52}\right.$

Para aquella época existían tres tipos de escuelas divididas por géneros: elementales, superiores e infantiles. En las primeras estaba previsto que los niños y niñas aprendiesen doctrina cristiana y las nociones de historia sagrada; lectura corriente, en impresos y manuscritos; ortología (sic); escritura forma inglesa: ortografía. Además, aritmética en sus operaciones fundamentales sobre números enteros y complejos; el sistema métrico» y se completaba con los elementos de la Historia Argentina y la explicación de los deberes y derechos del ciudadano. En las escuelas superiores debían perfeccionarse los estudios hechos en las elementales, ampliando la instrucción religiosa, la lengua nacional, el estudio de la Aritmética, los principios de geografía aplicados a la República; geometría y dibujo lineal, historia nacional y de la constitución política y música vocal. En lo que se refería a las escuelas de niñas,

${ }^{51}$ Mariquita Sánchez, Cartas de Mariquita Sánchez. Compilación, prólogo y notas de Clara Vilaseca (Buenos Aires, Peuser, 1952): 364-365.

${ }^{52}$ AHPBA: Recopilación de leyes y decretos: 1865, p. 52 
elementales o superiores, se daría la misma enseñanza que en las de varones, con el agregado de la práctica de «labores propias del sexo». Respecto de las escuelas infantiles, cubrían la franja etaria de cuatro a siete años y sólo se establecían en las poblaciones que alcanzaran los diez mil habitantes, situación inexistente en los partidos donde concentramos nuestro análisis. ${ }^{53}$

Los preceptores y maestras de aquellas escuelas tuvieron que batallar incansablemente para ganarse la confianza de los padres de familia y el respeto de los vecinos. Así como la escuela fue cuestionada porque transmitía saberes que poco tenían que ver con su suerte futura, también los maestros fueron criticados por interferir con la autoridad de los padres. Sin embargo, no dejaron de acudir a la prensa local para publicar avisos donde se invitaba a los padres para que llevaran a sus hijos a las escuelas. ${ }^{54} \mathrm{O}$ para reclamar que, «debían servirse de enviarlos con puntualidad al toque de la campana». ${ }^{55}$

Una difícil situación se les planteaba a los preceptores cuando se comprobaba que, en las elecciones, votaban por un candidato opositor a las autoridades gobernantes. Según se decía, en esas circunstancias, «se pierde la gracia y los méritos hechos en los años transcurridos, quedando reducido, si no quiere verse en este caso, no como un ciudadano hijo de un país libre sino como el más vil vasallo». ${ }^{56}$

La vulnerabilidad de su situación se hacía también evidente a la hora de evaluar su tarea en la escuela. En el momento de los exámenes, la institución recibía la visita de extraños, presidida frecuentemente por el cura, que poco conocían de la enseñanza y que producirían cierto temor en los escolares. Según las propias denuncias de los preceptores, además de la poca idoneidad de los improvisados examinadores y de las pregun-

\footnotetext{
${ }^{53}$ Cfr: Fundación de Escuelas Públicas en la Provincia de Buenos Aires...p. 87.

${ }^{54}$ Se encuentran avisos como los siguientes: «Escuela de Canchillo. El que suscribe avisa que la escuela está abierta para todos los niños del distrito, desde las 9 de la mañana hasta las dos de la tarde. Enseñanza gratis. Tomás D’Ambra». El Monitor de la Campaña, Año I, n. ${ }^{\circ} 2,3$ de julio de 1871. Este periódico fue publicado en la comunidad de Capilla del Señor Exaltación de la Cruz (entre 18711873) y su Director fue Preceptor y Director de la Escuela Urbana Elemental ubicada en la Plaza de la Concordia. Según se le reconocía, gracias a su iniciativa, se fundó la primera biblioteca popular de la campaña y el periódico que fue el primero de la campaña. En adelante: El Monitor.

${ }^{55}$ El Monitor, Año I, n. ${ }^{\circ}$ 4, 17 de julio de 1871.

${ }^{56}$ El Monitor, Año II, n. ${ }^{\circ} 37,4$ de marzo de 1872.
} 
tas extemporáneas que solían hacer, no se podía lucir el trabajo realizado a lo largo de todo el año.

Sobre esas prácticas docentes se cuenta con una información bastante fragmentaria registrada por los inspectores. En sus visitas se informaba sobre la pobre infraestructura escolar, donde se detecta que la mayoría de los edificios se alquilaban y las menos pertenecían a las municipalidades, la cantidad de niños y niñas que asistían, las condiciones de los preceptores y, por último, sobre el tipo de enseñanza.

El desconcierto y las expectativas no cumplidas promovían el cruce de acusaciones. Los personajes reconocidos, y de peso en su opinión, de las comunidades exigían más compromiso de las autoridades. Por su parte, las autoridades reclamaban a los padres para que asumieran la responsabilidad de educar a sus hijos. Con todo, se llegaba a la conclusión que, frente al número de niños y niñas sin recibir instrucción, deberían ser las propias autoridades municipales las que tenían las mejores condiciones para ponerse al frente de la tarea. Así lo hicieron en muchos pueblos. Uno que ha dejado registro de ese incansable emprendimiento fue el dinámico poblado de Exaltación de la Cruz. Sus dirigentes asumieron el protagonismo al abrir nuevas escuelas en el partido. Tal parece que, la iniciativa habría llevado a que 236 varones recibieran instrucción, mientras que no recibían ninguna unos 227. En cuanto a las niñas, 170 estaban escolarizadas y 208 no tenían ningún tipo de instrucción. De esos datos concluían que, se había disminuido la cantidad de niños y niñas analfabetos a 435 - mientras que para 1869 , se mencionaba que existían $614-{ }^{57}$

Esas medidas promovidas por las corporaciones municipales trascendían lo estrictamente educativo, poniendo en escena la disputa política con las autoridades del gobierno provincial. Eran tiempos en los que, por un lado, el gobierno de Buenos Aires se arrogaba el derecho de designar al Juez de Paz como Presidente del Municipio y, por otro, las propias autoridades de la provincia - en varias oportunidades- llamaron la atención a los municipios de los pueblos para recordar que,

${ }^{57}$ El Monitor, Año I, n. ${ }^{\circ}$ 18, 23 de octubre de 1871. Se debe dejar constancia que, en esos meses, hubo un incremento en la inasistencia de escolares debido a la epidemia de viruela que, incluso, llevó a cerrar algunos de los establecimientos de la zona. 
[...] las Municipalidades pongan todos sus medios al servicio de la educación, pero subordinándose a la alta inspección del Departamento General de Escuelas, en todo lo que es de su atribución, según las disposiciones vigentes [...] La dirección de las Escuelas Públicas, no es posible que se lleve a una descentralización tal que cada uno sea el árbitro de llevarla según sus propias ideas, la ley es quien la regla [...] Atribución reconocida expresamente en la Ley del Presupuesto, y en la de la Municipalidad de Buenos Aires. ${ }^{58}$

Se afirmaba que las relaciones entre la Dirección de Escuelas y las Municipalidades eran solo nominales. Supuestamente, si las autoridades municipales querían conocer sobre el régimen horario, los planes de estudio y otras cuestiones que hacía a lo educativo debían dirigirse al Preceptor. El Departamento se relacionaba directamente con los profesores y administraba así escuelas a más de 100 leguas de distancia. Sin embargo, tal como se planteaba, habría varios ensayos de escuelas fundadas y gobernadas por las municipalidades que habían confiado su dirección a personas de su misma vecindad. Así quedó registrado en este ilustrativo pasaje:

Las autoridades locales recomendaban a personas del mismo cuartel queridas y respetadas por sus vecinos, buscando como preferencia, señoras como más adecuadas y también para poder enseñar a los dos sexos. [...] Los Profesores que mandó el Departamento eran en su mayor parte extranjeros, que no habían atravesado seguramente el Océano para enseñar el A.B.C.D- Personas honradas sin duda, pero náufragos de la civilización que nos enseñan más fácilmente necesidades nuevas, que los medios de satisfacerlas —educaciones erradas: ni hombres de acción, ni hombres de ciencia. [...] La falta de vocación [...] es [...] la causa de la superioridad de las ordenes (sic) Religiosas como cuerpos de enseñanza, allí el espíritu del Cristianismo suple a la vocación si no existe, y hace cumplir los deberes con conciencia y escrupulosidad. [...] Un día vemos depositar dinero hasta que la cantidad

\footnotetext{
${ }^{58}$ AHPBA: Memorias de las Diferentes Reparticiones de la Administración de la Provincia y de varias Municipalidades de Campaña. Buenos Aires: Imprenta de Buenos Aires, 30 de marzo de 1868, p. 92.
} 
alcance para construir una escuela sobre el modelo de las de Norte América, otro día vemos que se pide maestros a Norte América. [...] eso es cosa que no se explica. Si fuese para hacerlas sobre el modelo de la escuela donde se educó Leibnitz o Voltaire, casi comprendería el fetiquismo ( $\mathrm{sic}$ ), pero sobre el modelo $\mathrm{N}$. Americano!

[...] Para el adelanto de los estudios cada sección debe tener su sala, con este sistema ganan no solamente los estudios sino la higiene y la disciplina, todo lo contrario que lo que hace hoy con esas grandes salas donde se amontonan 80 a 100 niños, unos estudiando el silabario, otros la gramática, otros aritmética, todos a un tiempo durante las 5 horas escolares. [...] La sola compensación que hoy nos queda es que nuestra instrucción primaria se llama hoy educación común como en Norte América y nuestras escuelas se llaman salones, como en Norte América. El culto de Bubda! ${ }^{59}$

Críticas e ironías que dan cuenta del interés por preservar un espacio de poder conseguido o, en su defecto, conseguir nuevas alianzas clientelares y políticas en el marco de ese escenario de conformación del Estado Nacional. Ante el avance de la administración central en el control de las escuelas, la prensa facciosa no se privó de exponer situaciones como las siguientes:

El viajero que entra por primera vez en una escuela de nuestra campaña recibe las impresiones siguientes. El edificio hace contraste con las modestas habitaciones que lo rodean, el interior corresponde al exterior; la sala es alta, espaciosa y muy limpia, se ve que la importancia del edificio ha estimulado el celo del maestro y la impresión de la entrada es muy agradable. Más si se procede al examen de los alumnos las impresiones de la entrada no tardan en modificarse. Niños de 15 años con 7 años de escuela no poseen más que los conocimientos que proporcionan en dos años los sistemas más defectuosos [...] El tiempo de los estudios diarios está fijado por el Departamento en 5 horas [...] podemos desde ya asegurar que el reglamento no se cumple [...]. El siste-

\footnotetext{
${ }^{59}$ El Monitor, Año II, n. ${ }^{\circ}$ 30, 13 de enero de 1872.
} 
ma de emplear los alumnos más adelantados como monitores de los demás hace que queden estacionarios en sus estudios [...] La cuestión de los textos necesitan grandes reformas [...] En nuestras escuelas no se lee el evangelio [...] El joven de 13 o 14 años sale sin saber si es la tierra o el sol el que se mueve, si la tierra es cuadrada o redonda. La sociedad debe sentir que no se le haya enseñado más bien un oficio». ${ }^{60}$

\section{EPÍLOGO}

La voluntad de las autoridades de turno, y el tipo de acciones que promovieron en materia de instrucción, no siempre estuvo en consonancia con los intereses de los referentes de las comunidades. La inestable presencia de las autoridades estatales, las muchas veces cuestionada figura de los preceptores y el peso del entramado social y político de las comunidades hizo azarosa y, a veces, errática la presencia de esas escuelas de primeras letras. La presión de figuras notables de las comunidades - curas, jueces de paz y padres de escolares-, impuso condicionamientos a las decisiones de las autoridades de turno. La escuela, maestros y maestras, participaron de una suerte de teatro social, donde los distintos actores dieron cuenta de su capacidad de agencia para resistir, mediar y negociar. De allí que, resulta válido pensar en el lugar que ocupó esa escolarización a la hora de rastrear ese proceso de configuración del poder estatal y su relación con la sociedad civil.

Un punto de inflexión se concretó cuando el Gobierno de la Provincia de Buenos Aires - durante la segunda gestión de Sarmiento como Director del Departamento de Escuelas- sancionó la Ley de Educación Común, gratuita y obligatoria en 1875 , una normativa que, por otra parte, garantizó la enseñanza religiosa en las aulas. ${ }^{61}$ La sanción de esta Ley otorgó, por lo menos en la letra, una gran responsabilidad a la sociedad civil al entregarle el control educativo a través de los Consejos Escolares, compuestos por vecinos elegidos por sus propias comunidades. Sin embargo, para muchos, esta ley implicó limitar su campo de acción al

${ }^{60}$ El Monitor, Año II, n. ${ }^{\circ}$ 33, 3 de febrero de 1872.

${ }^{61}$ Aunque excede este trabajo, por aquellos años Sarmiento, había iniciado su batalla en la prensa favor de la educación laica, sin embargo, no pudo concretarla en la ley. 
imponer un modelo educativo que dejaba poco margen para las iniciativas locales concretas que antaño habían existido más allá de la "ficción» democrática que suponía que los vecinos elegían a sus representantes en los concejos escolares. Para otros, lo inacabado de la tarea, frente a los magros resultados que se exponían en los informes sobre índices de alfabetización, exigía una mayor presencia del Estado.

Aquella fue una razón que esgrimió el Estado Nacional al sancionar la Ley de Educación común, gradual, gratuita, obligatoria en 1884, sobre la que se asentó la tradición laica de las escuelas nacionales. Más allá de reconocer la autonomía educativa de las provincias, en la práctica, avanzó con la presencia de educadores normalistas y la posterior radicación de escuelas primarias nacionales con la sanción de la Ley Láinez en 1905 que compitieron con las provinciales.

\section{Nota sobre la autora}

Lucía LiOnetTi es Doctora en Historia por la Universidad Autónoma de Madrid. Profesora y Licenciada en Historia por la UNCPBA. Docente Titular Ordinaria del Departamento de Historia de la FCH-UNCPBA. Directora del Instituto de Estudios Histórico Sociales «Prof. Juan Carlos Grosso» (IEHS). Línea de investigación desarrollada: Historia Social y Cultural de la Educación en Argentina, fines del siglo XIX y albores del Siglo Xx. El magisterio, agente político e intelectual en Argentina fines del siglo XIX y primeras décadas del xx. En la actualidad se estudia: las escuelas, las infancias y el género en la campaña bonaerense siglos XVIII y XIX. De estas líneas de trabajo se han publicado libros como autora, editora y compiladora; capítulos de libros y artículos a nivel nacional e internacional (España, EEUU, Brasil, México, Chile, Colombia). Entre los libros publicados como autora se pueden citar: La misión política de la escuela pública: formar al ciudadano de la República (Buenos Aires, Editorial Miño y Dávila, 2007). Como compiladora (junto a Daniel Míguez), Las Infancias en la Historia Argentina. Intersecciones entre Prácticas, Discursos e Instituciones (1890-1960) (Buenos Aires: Prohistoria, 2010). Como compiladora (junto a María Ana Manzione y Cecilia Di Marco) Infancia, juventud y educación en diálogo. Aproximaciones y enfoques interdisciplinares (Buenos Aires: Editorial La Colmena, 2012). Como coordinadora (junto a Alicia Civera Cerecedo y Flavia Werle, Escuelas, comunidades rurales y sujetos sociales en América 
Latina (México: El Colegio Mexiquense-Colegio de Michoacán-Prohistoria, 2013). En colaboración con Silvia Castillo, Historia Regional de la Educación en La Pampa (Editorial UNLPam, Santa Rosa, 2015).

\section{Referencias}

Arredondo, Adelina. En la senda de la Modernidad. Un siglo de Educación en Chihuahua, 1767-1867. 2 Tomos. Michoacán: El Colegio de Michoacán, 2011.

BARBA, Fernando. «Un aspecto poco conocido del ideario de Sarmiento. El desarrollo educativo basado en la creación de rentas propias a la educación pública». Anales 41 (2011): 4-13.

BARral, María Inés. De sotanas por la Pampa. Religión y Sociedad en el Buenos Aires rural tardocolonial. Buenos Aires: Prometeo, 2007.

BARRIERA, Darío. «Tras las huellas de un territorio». In De la Conquista a la Crisis de 1820. Colección Historia de la Provincia de Buenos Aires, edited by Juan Manuel Palacio y Raúl Fradkin, 53-84. Tomo 2. Buenos Aires: Editorial Universitaria EDHASA, 2012.

BiLbAO, Luca. "Gringos” en la frontera: los curas del Tandil y el Azul en la segunda mitad del siglo XIX». Revista Folia Histórica del Nordeste. Instituto de Investigaciones Geohistóricas (Conicet-UNNE) e Instituto de Historia, Facultad de Humanidades (UNNE) (2015): 243-264.

BJerg, María Mónica. El mundo de Dorotea. La vida en un pueblo de la frontera de Buenos Aires en el siglo XIX. Buenos Aires: Imago Mundi, 2004.

Bohoslavsky, Ernesto y Milton Godoy Orellana, eds. Construcción estatal, orden oligárquico y respuestas sociales: Argentina y Chile, 1840-1930. Buenos Aires: Prometeo Libros-Universidad Nacional de General Sarmiento, 2010.

Bustamante Vismara, José. Las escuelas de primeras letras en la campaña de Buenos Aires (1800-1860). La Plata: Asociación Amigos del Archivo Histórico, 2007.

- «Construcción estatal y desarrollo escolar (Córdoba, Buenos Aires y Entre Ríos), 1820-1850». Historia de la Educación, Anuario SAHE (Argentina) 17 (1), (2016): 50-71.

CAnsanello, Carlos. De súbditos a ciudadanos. Ensayo sobre las libertades en los orígenes republicanos. Buenos Aires, 1810-1852. Buenos Aires: Imago Mundi, 2003.

- «Las milicias rurales bonaerenses entre 1820-1830». Cuadernos de Historia Regional 19 (1998): 7-51.

FRADKIN, Raúl. "Cultura jurídica y cultura política: la población rural de Buenos Aires en una época de transición (1780-1830)». In La ley es tela de araña. Ley, 
Justicia y Sociedad Rural en Buenos Aires, 1780-1830, edited by Raúl Fradkin, 159-186. Buenos Aires: Prometeo, 2009.

FRADKIN, Raúl. «Entre la ley y la práctica: la costumbre en la campaña bonaerense de la primera mitad del siglo XIX». Anuario IEHS 12 (1997), 141-156.

Fuente, Ariel de la. Los hijos de Facundo. Caudillos y montoneras durante el proceso de formación del Estado Nacional Argentino (1853-1870). Prometeo: Buenos Aires, 2007.

GARAVAgLiA, Juan Carlos. "Ámbitos, vínculos y cuerpos. La campaña bonaerense de vieja colonización». In Historia de la vida privada en la Argentina, edited by Fernando Devoto y Marta Madero, 104-124. Tomo I. Buenos Aires: Taurus, 1999.

- «Ejército y milicia: los campesinos bonaerenses y el peso de las exigencias militares, 1810-1860». Anuario IEHS 18 (2003): 153-187.

- «La apoteosis del Leviatán: el Estado en Buenos Aires durante la mitad del siglo XIX». American Research Review 38 (1), (2003):135-168.

Gelman, Jorge. «La construcción del orden poscolonial. El «sistema de Rosas» en Buenos Aires entre la coerción y el consenso». Tiempos de América 11 (2004): 27-44.

GuHA, Ranahit. Las voces de la historia y otros estudios subalternos. Barcelona: Editorial Crítica, 2002.

Halperín Donghi, Tulio. Revolución y Guerra. Formación de una elite en la Argentina criolla. Buenos Aires: Siglo XXI, 2005.

Jojot, María Cristina. «La Sociedad de Beneficencia de Buenos Aires. Conversaciones, administración y tutela en los años fundacionales 1823-1835». PhD diss., Universidad de San Andrés, 2017.

LioneTti, Lucía. «Cuerpo y castigo. La penalidad física en las escuelas elementales de Buenos Aires y la campaña en el siglo XIX». Quinto Sol 19 (2), (2015): 1-21.

- «Las Damas de la Sociedad de Beneficencia educan a las hijas de la campaña bonaerense (1852-1875)». In La educación rural en América Latina siglo XIX y XX, edited by Flavia Obino Correa Werle, 175-195. Brasilia: Editorial Liber Libros, 2010.

- «Las escuelas de primeras letras en el escenario social de la campaña bonaerense (1850-1875)». Naveg@merica. Revista Española de la Asociación de Española de Americanistas, Universidad de Murcia 4 (2010). http://revistas. um.es/navegamerica/article/view/99851

MAC CANN, Willian. Viaje a caballo por las provincias argentinas. Buenos Aires: Taurus, 2001.

Mallon, Florence. Peasant and Nation. The making of Postcolonial México and Perú. Bekerley: University of California Press, 1994. 
MANDRINI, Raúl. «Indios y fronteras en el área pampeana (siglos XVI y XIX). Balance y perspectivas». Anuario IEHS 7 (1992): 59-72.

MAssÉ, Gladys. «El tamaño y el crecimiento de la población desde la Conquista hasta 1870». In Población, ambiente y territorio, edited by Hernán Otero, 143172. Tomo 1. Buenos Aires: Editorial Universitaria EDHASA, 2012.

MAYO, Carlos. Vivir en la frontera. La casa, la dieta, la pulpería, la escuela (17701870). Buenos Aires: Biblos, 2002.

Meglio, Gabriel di. ;Viva el bajo pueblo! La plebe urbana de Buenos Aires y la política entre la Revolución de Mayo y el rosismo. Buenos Aires: Prometeo, 2007.

Moreno, José Luis y José A. MATEO. «El redescubrimiento de la demografía histórica en la historia económica y social». Anuario IEHS 12 (1997): 23-62.

Newland, Carlos. «La educación elemental en Hispanoamérica: desde la independencia hasta la centralización de los sistemas educativos nacionales». The Hispanic American Historical Review 71 (2), (1992): 335-364.

ORTELli, Sara y Silvia RATTO. «Introducción dossier: Poder, conflicto y redes sociales en la frontera pampeana, siglos XVIII-XIX». Trabajos y Comunicaciones 32/33 (2006): 77-85.

Palacio, Juan Manuel Palacio. La paz del trigo. Cultura legal y sociedad local en el desarrollo agropecuario pampeano, 1890-1945. Buenos Aires: Edhasa, 2004.

QuiJADA, Mónica. «Sobre «nación», "pueblo», "soberanía»y otros ejes de la modernidad en el mundo hispánico». In Las nuevas naciones. España y México, 1800-1850, edited by Jaime E. Rodríguez, 19-51. Madrid: Mapfre Editores, 2008.

SÁnchez, Mariquita. Cartas de Mariquita Sánchez. Compilación, prólogo y notas de Clara Vilaseca. Buenos Aires: Peuser, 1952.

YANGILEVICH, Melina y Eduardo MíGuez. "Justicia criminal y Estado en la frontera de Buenos Aires, 1852-1880». Boletín del Instituto de Historia Argentina y Americana «Dr. Emilio Ravignani» 32 (2010): 107-130.

Zanatta, Loris y Roberto Di Stefano. Historia de la Iglesia Argentina. Desde la Conquista hasta fines del siglo XX. Buenos Aires: Grijalbo, 2000. 